\title{
High $\kappa$ free light chain is a potential biomarker for double seronegative and ocular myasthenia gravis
}

Adi Wilf-Yarkoni, MD, Yifat Alkalay, PhD, Talma Brenner, PhD, and Arnon Karni, MD, PhD

Neurol Neuroimmunol Neuroinflamm 2020;7:e831. doi:10.1212/NXI.0000000000000831

\section{Abstract}

\section{Objective}

To investigate the hypothesis that free light chain (FLC) sera levels could serve as a biomarker for myasthenia gravis (MG), especially for the subgroups of seronegative MG and ocular MG.

\section{Methods}

Sera from 73 patients with MG (20 seronegative for antiacetylcholine receptor [AChR] and anti-muscle-specific kinase and 53 positive for anti-AChR, which were clinically divided into 24 patients with ocular type, 45 with generalized type, and 4 with unequivocal clinical manifestation) and 49 healthy controls were studied for $\kappa$ FLC and $\lambda$ FLC levels with the Freelite human FLC kits.

\section{Results}

The $\kappa$ but not the $\lambda$ levels of FLC were significantly increased in the patients with MG, including those with double seronegative MG and ocular MG, compared with the healthy controls. The specificity for double seronegative MG and ocular MG were both 98.0\% when $\kappa$ FLC was $\geq 25.0$ $\mathrm{mg} / \mathrm{L}$. Increased $\kappa$ FLC levels were not affected by the patient's sex, age at MG onset, the presence of thymic pathology, or different treatments.

\section{Conclusions}

Elevated serum $\kappa$ FLC may serve as a biomarker for MG in suspected patients who are double seronegative and in those with only ocular manifestations when serology is inconclusive.

\section{Classification of evidence}

This study provides Class III evidence that high $\kappa$ FLC levels distinguished patients with MG, including those who were double seronegative, from healthy controls.

\author{
Correspondence \\ Dr. Karni \\ arnonk@tlvmc.gov.il
}

\section{MORE ONLINE}

$\rightarrow$ Class of Evidence

Criteria for rating therapeutic and diagnostic studies

NPub.org/coe 


\section{Glossary}

$\mathbf{A C h R}=$ acetylcholine receptor; $\mathbf{A N A}=$ antinuclear antibody; $\mathbf{A R R}=$ absolute risk reduction; $\mathbf{E N A}=$ extracted nuclear antibody; FLC = free light chain; G-MG = generalized myasthenia gravis; HC = healthy control; IVIg = IV immunoglobulin; LRP4 = lipoprotein receptor-related protein 4; MG = myasthenia gravis; MuSK = muscle-specific kinase; NNT = number needed to treat; $\mathbf{O}-\mathbf{M G}=$ ocular myasthenia gravis; $\mathbf{R O C}=$ receiver operating characteristic; $\mathbf{S N}-\mathbf{M G}=$ serum-negative myasthenia gravis; SP-MG = serum-positive myasthenia gravis; $\mathbf{T P O}=$ thyroid peroxidase.

Myasthenia gravis (MG) is an antibody-mediated autoimmune disease affecting the postsynaptic neuromuscular junctions of striated skeletal muscles. ${ }^{1-3}$ The clinical manifestation includes muscle weakness, which can be localized to ocular muscles (ocular MG [O-MG]) or distributed in extraocular muscles (generalized MG [G-MG]). ${ }^{2}$ The diagnosis of $M G$ is confirmed by the combination of symptoms, electrical physiologic studies demonstrating neuromuscular junction dysfunction, and a positive test for specific antibodies. ${ }^{4,5}$ Antibodies against acetylcholine receptors (AChRs), ${ }^{6}$ muscle-specific kinase (MuSK), ${ }^{7}$ and lipoprotein receptor-related protein 4 (LRP4) $)^{3,8}$ can be found in about $90 \%$ of patients with MG (seropositive [SP]), and about $10 \%$ remain with undetected specific autoantibody (seronegative $[\mathrm{SN}]) .{ }^{1}$ The diagnosis of MG may be obscure in $\mathrm{SN}$ patients. The failure in finding a specific antibody for MG leaves a degree of insecurity in the diagnosis of SN-MG, and it is recommended that serologic tests be repeated several months following negative test results. ${ }^{1}$ A biomarker for MG in these patients may therefore add confidence in the diagnosis of MG.

The production of antibodies is generally also accompanied by the synthesis of immunoglobulin light chains. The circulating levels of light chains may be increased in conditions of excess immunoglobulin production, as in antibody-mediated diseases and in renal failure. ${ }^{9,10}$ Recent studies have demonstrated that this overproduction of light chains has a biological and immunologic role. ${ }^{9}$ An increase in free light chain (FLC) production has been reported in several autoimmune diseases. ${ }^{11-17}$

To the best of our knowledge, only 1 study has evaluated FLC levels in MG, and it reported an elevation of both $\kappa$ FLC and $\lambda$ FLC in their 34 study patients. ${ }^{18}$ We hypothesized that $\kappa$ FLC and $\lambda$ FLC levels may be biomarkers for MG, especially for SN-MG for which diagnosis can be difficult. Therefore, we studied the $\kappa$ FLC and $\lambda$ FLC levels in patients with MG, including those with SN-MG, and in healthy controls (HCs). We also analyzed the results according to various clinical forms of the disease in a large number of patients with MG.

\section{Methods}

\section{Standard protocol approvals, registrations, and patient consent}

The study protocol was approved by the Tel Aviv Sourasky Medical Center Institutional Review Board for human experiments (Helsinki Committee, No. 0702-15). All the participants signed written informed consent.

\section{Study design}

This is a case-control prospective study that compares the levels of FLCs in the sera of patients with MG and of HCs.

\section{Patients and controls}

One hundred twenty-eight potential donors who include 79 consecutive patients with MG and 49 healthy volunteers were screened. Sixteen of the patients were excluded (because of the exclusion criteria that are listed below and in the flow diagram [supplementary data, links.lww.com/NXI/A281]). To increase the number of subjects with SN-MG, we invited an additional 10 patients who were known to have SN-MG to participate in the study. Overall, blood samples were drawn between 2017 and 2019 from 73 patients with MG who were referred to the Neuroimmunology Unit at the Tel Aviv Sourasky Medical Center, Tel Aviv, Israel, and from 49 healthy individuals who served as controls (HCs) (table). The diagnosis of MG was defined by clinical and supportive features of neurophysiology tests of single-fiber EMG and/or serology of AChR antibodies or anti-MuSK antibodies. The patients underwent a chest CT scan or a chest MRI scan, and those with radiologic evidence of thymus enlargement or a suspected thymoma underwent thymectomy.

The distribution of patients according to the Myasthenia Gravis Foundation of America clinical classification was Class $\mathrm{I}=24$ patients, Class IIA $=20$ patients, Class IIB $=4$ patients, Class IIIA $=9$ patients, Class IIIB $=6$ patients, Class IVA $=4$ patients, and Class IVB $=2$ patients. The classification of 4 patients was equivocal. Class I, which is ocular MG (O-MG), was diagnosed in patients with pure ocular involvement lasting over 2 years because $90 \%$ of them will be presumed to remain with ocular MG throughout their illness. ${ }^{19}$ The disease duration among these patients was between 2 and 3 years in 2 patients, between 3 and 5 years in 6 patients, and above 5 years in 16 patients.

The diagnosis of patients with SN-MG was based on fluctuating muscular weakness in a typical distribution for $\mathrm{MG}$ with supportive positive diagnostic tests of single-fiber EMG and/or repetitive stimulation EMG and/or positive edrophonium tests in addition to ruling out other relevant medical conditions that may present with the same type of weakness (such as thyroid ophthalmopathy, congenital myasthenia, Lambert-Eaton myasthenic syndrome, myositis, mitochondrial syndromes, amyotrophic lateral sclerosis, and CNS demyelinating diseases) by the clinical presentation and course, relevant blood tests, EMG, and brain MRI in 
Table Demographic and clinical characteristics of the patients

\begin{tabular}{|c|c|c|c|c|}
\hline & $\mathbf{N}$ & Male & Female & Age at onset, $y$ \\
\hline Ocular MGa & 24 & 16 & 8 & $62.4 \pm 16.7$ \\
\hline Generalized $\mathbf{M G}^{\mathrm{a}}$ & 45 & 25 & 20 & $56.1 \pm 16.8$ \\
\hline Early-onset MG (age $\leq 50$ y) & 21 & 11 & 10 & $38.1 \pm 10.8$ \\
\hline Late-onset MG & 52 & 31 & 21 & $66.8 \pm 10.8$ \\
\hline Seropositive for AChR & 53 & 34 & 19 & $57.8 \pm 17.2$ \\
\hline Double seronegative (anti-AChR and anti-MuSK) & 20 & 8 & 12 & $60.7 \pm 16.5$ \\
\hline Thymus pathology & 12 & 5 & 7 & $40.2 \pm 14.2$ \\
\hline Total MG & 73 & 42 & 31 & $58.6 \pm 16.9$ \\
\hline Healthy controls & 49 & 21 & 28 & $43.4 \pm 12.9^{b}$ \\
\hline
\end{tabular}

Abbreviations: AChR = acetylcholine receptor; MG = myasthenia gravis; MuSK = muscle-specific kinase .

a The clinical manifestation was unequivocal for 4 patients.

${ }^{\mathrm{b}}$ Age at sampling.

patients who had negative tests for anti-AChR and antiMuSK antibodies. Patients were treated according to the accepted guidelines.

The exclusion criteria were a diagnosis of plasma cell dyscrasia disorders, a diagnosis or suspicion of another chronic inflammatory condition known to be associated with increased serum levels of FLC (such as rheumatoid arthritis, systemic sclerosis, Sjögren syndrome, and systemic lupus erythematosus), ${ }^{10,14}$ a glomerular filtration rate of $<60 \mathrm{~mL} /$ $\min / 1.73 \mathrm{~m}^{2}$, and treatment with plasmapheresis for the past 3 months. We recruited healthy individuals to serve as the control group to test whether FLC levels are high in the sera of patients with MG. The data collection was planned before the tests for FLCs were performed.

\section{Laboratory testing}

Blood serum samples were separated by standard centrifugation, divided into aliquots, and stored frozen until analysis. The samples were then assayed in a blinded fashion. FLC serum levels were assessed with the Freelite Human $\kappa$ and $\lambda$ Free Kits (The Binding Site Ltd., Birmingham, United Kingdom) on a SPAPLUS instrument (The Binding Site Ltd.). Anti-AChR Ab was tested by ELISA (EUROIMMUN AG, Luebeck, Germany). Anti-MuSK Ab was assessed by RIA with the MuSK kit (RSR Ltd., Cardiff, United Kingdom). Antinuclear antibody (ANA), antimitochondrial, and antismooth muscle were tested by immunofluorescence (AESKU GROUP, Wendelsheim, Germany). Extracted nuclear antibodies (ENAs) including antibodies against SSA, SSB, RNP SM, JO1, and SCL70, as well as antibodies against histone, dsDNA, thyroglobulin, and thyroid peroxidase (TPO), were tested by ELISA (Alegria by ORGENTEC Diagnostika GmbH, Mainz, Germany). Rheumatoid factor was assessed by a nephelometric $\mathrm{BN}^{\mathrm{tm}}$ II System by Siemens Medical Solutions, Malvern, PA.

\section{Primary research questions}

Can $\kappa$ FLC and $\lambda$ FLC levels be biomarkers for patients with MG and for patients with double SN-MG.

\section{Statistical analysis}

Data for group comparisons are presented as mean \pm SD and with $95 \%$ confidence intervals (CIs). Statistical analysis and the graphical representation of the data were performed with GraphPad Prism (version 8.2.1; GraphPad Software, San Diego, CA), SPSS (version 22; SPSS Inc., Chicago, IL). Comparisons between 2 groups were performed using the Student unpaired $t$ test with Welch's correction when the variances were unequal. The Welch analysis of variance test was applied to compare multiple group differences for unequal variance, and the Dunnett T3 multiple comparisons test was used to compare withingroup differences. A $p$ value of $<0.05$ was considered statistically significant. A multivariate analysis was performed to evaluate possible confounding effects. A receiver operating characteristic (ROC) curve analysis for calculating the area under the ROC curve was used to determine the diagnostic accuracy of FLC values as diagnostic markers for MG. The number needed to treat $(\mathrm{NNT})$ and absolute risk reduction (ARR) were added when an estimation of cutoff levels of FLC was analyzed. The Pearson correlation coefficient was applied to test correlations between anti-AChR and FLC levels.

\section{Data availability}

Anonymized data will be shared by request from any qualified investigator.

\section{Results}

The 122 participants in this study included 73 patients with MG (42 men and 31 women), with a mean age of (mean \pm SD) $59.1 \pm 14.2$ years, and $49 \mathrm{HCs}$ ( 21 men and 28 women) with 
a mean age of $43.4 \pm 12.8$ years. The patients' clinical manifestations, serologic results, sex, and age at MG onset are summarized in table. There were 53 patients with detectable anti-AChR antibodies in the serum and 20 patients with negative results for anti-AChR and anti-MuSK.

\section{FLC levels in patients with MG and according to serologic status}

The $\kappa$ FLC serum levels were higher in the patients with MG compared with the HCs $(23.7 \pm 8.3 \mathrm{mg} / \mathrm{L}, \mathrm{CI}=21.8-25.68$ $\mathrm{mg} / \mathrm{L}$ and $15.9 \pm 5.0 \mathrm{mg} / \mathrm{L}, \mathrm{CI}=14.5-17.3 \mathrm{mg} / \mathrm{L}$, respectively, $p<0.0001$, figure 1A). However, there were no significant differences in their $\lambda$ FLC serum levels $(15.9 \pm 5.7 \mathrm{mg} / \mathrm{L}, \mathrm{CI}=$ $14.6-17.2 \mathrm{mg} / \mathrm{L}$ and $14.5 \pm 4.6 \mathrm{mg} / \mathrm{L}, \mathrm{CI}=13.2-15.8 \mathrm{mg} / \mathrm{L}$, respectively, $p=$ N.S., figure $1 \mathrm{~B})$. Moreover, there was a significant increase in the $\kappa / \lambda$ ratio in the patients with MG compared with the HCs $(1.5 \pm 0.41, \mathrm{CI}=1.4-1.6$ and $1.1 \pm 0.2$, $\mathrm{CI}=1.0-1.2$, respectively, $p<0.0001$, figure $1 \mathrm{C})$. These increased $\kappa$ FLC levels in the patients with MG compared with the HCs were confirmed after correction for age and sex in a multivariant analysis $(F=16.34, p<0.001)$.

One of the main objectives of this study was to test the FLC serum levels in patients who tested negative for antibodies against both AChR and MuSK (double SN-MG). The $\kappa$ but not the $\lambda$ FLC levels differed significantly among the 3 groups $(p<0.0001)$. A multiple comparisons test revealed a significant increase in $\kappa$ FLC in the patients with double SN-MG $(n=20$, $26.8 \pm 12.0 \mathrm{mg} / \mathrm{L}, \mathrm{CI}=21.5-32.0 \mathrm{mg} / \mathrm{L}$ ) compared with the HCs $(p<0.002$, figure 1D). There was no significant difference in $\kappa$ FLC levels between double SN patients and SP patients for anti-AChR ( $\mathrm{n}=53,22.5 \pm 6.2 \mathrm{mg} / \mathrm{L}, \mathrm{CI}=20.8-24.2 \mathrm{mg} / \mathrm{L}, p=$ N.S.). The $\kappa / \lambda$ ratio, however, differed significantly among the 3 groups $(p<0.0001)$. There was a significant increase in the $\kappa / \lambda$ ratio in the patients with SN-MG $(1.6 \pm 0.5, \mathrm{CI}=1.4-1.9)$ compared with the HCs $(p<0.001$, figure $1 \mathrm{~F})$. None of the study patients were found to have anti-MuSK antibodies.

The difficulties in diagnosing MG in patients who have negative serology tests for myasthenia-specific autoantibodies establish a clear-cut need for a biomarker(s) for this patient subgroup. A ROC analysis for $\kappa$ FLC in patients with double SN-MG has an area under the curve of $0.79, \mathrm{CI}=0.65-0.91$, $p=0.0002$ (figure $1 G$ ). For example, the calculated specificity of $\kappa$ FLC $\geq 25 \mathrm{mg} / \mathrm{L}$ of patients with double SN-MG compared with HCs was $98.0 \%$, with a sensitivity of $45.0 \%$, $\mathrm{NNT}=2.2$, and $\mathrm{ARR}=-0.45$.

The sera of all patients with double SN-MG were tested for ANA, ENA (that includes antibodies against SSA, SSB, RNP, SM, JO1, and SCL70), antibodies against histone, dsDNA, thyroglobulin, TPO, mitochondrial, smooth muscle, and rheumatoid factor. We found that 1 patient was positive for ANA (homogenous pattern), anti-dsDNA, and anti-histone ( $\kappa$ $\mathrm{FLC}=15.5 \mathrm{mg} / \mathrm{L}$ and $\lambda \mathrm{FLC}=11.4 \mathrm{mg} / \mathrm{L})$. Another patient with double SN-MG was positive for TPO ( $\kappa \mathrm{FLC}=16.9 \mathrm{mg}$ ) $\mathrm{L}$ and $\lambda \mathrm{FLC}=11.7 \mathrm{mg} / \mathrm{L}$ ). We did not find any correlation between the levels of anti-AChR and $\kappa$ FLC $(r=-0.059)$ or $\lambda$ FLC $(r=-0.044)$.

\section{FLC levels in patients with MG according to clinical characteristics}

We compared the FLC levels in MG subgroups according to clinical manifestations, age at MG onset, and thymus pathology. Figure 2, A and B shows the $\kappa$ and $\lambda$ FLC levels in the O-MG, G-MG, and HC groups. The $\kappa$ FLC but not the $\lambda$ FLC levels differed significantly among the 3 groups $(p<0.0001)$. A multiple comparisons test revealed an increase in $\kappa$ FLC in the O-MG group $(\mathrm{n}=24,23.0 \pm 6.2 \mathrm{mg} / \mathrm{L}, \mathrm{CI}=20.0-25.0 \mathrm{mg} / \mathrm{L}$ ) compared with the HC group $(15.9 \pm 5.0 \mathrm{mg} / \mathrm{L}, \mathrm{CI}=14.5-17.3$ $\mathrm{mg} / \mathrm{L}$, figure $2 \mathrm{~A}$ ). There was no difference between the O-MG and $\mathrm{G}-\mathrm{MG}$ groups $(23.8 \pm 9.2, \mathrm{CI}=21.1-26.5 \mathrm{mg} / \mathrm{L})$.

Given that the diagnosis of ocular MG may often be challenging, there is a need for a biomarker for ocular MG. The ROC analysis for $\kappa$ FLC in patients with ocular MG had an area under the curve of $0.81,95 \% \mathrm{CI}=0.71-0.91$ (figure $2 \mathrm{C}$ ). For example, the calculated specificity of $\kappa$ FLC $\geq 25 \mathrm{mg} / \mathrm{L}$ of patients with O-MG compared with the HCs was $98.0 \%$, with a sensitivity of $37.5 \%, \mathrm{NNT}=2.7$, and ARR $=-0.375$. There was an increase in the $\kappa / \lambda$ ratio between $\mathrm{O}-\mathrm{MG}(1.5 \pm 0.5, \mathrm{CI}=$ $1.3-1.7)$ and $\mathrm{G}-\mathrm{MG}(1.5 \pm 0.4, \mathrm{CI}=1.4-1.6)$ groups and the HCs $(1.1 \pm 0.2, \mathrm{CI}=1.0-1.2)$.

Early-onset MG was defined as onset at $\leq 50$ years of age, and late-onset MG was defined as onset $>50$ years of age. ${ }^{5}$ There was also no difference in the $\kappa$ FLC and $\lambda$ FLC levels between patients with early-onset MG $(\mathrm{n}=21,20.9 \pm 6.5 \mathrm{mg} / \mathrm{L}, \mathrm{CI}=$ $18.1-23.6 \mathrm{mg} / \mathrm{L}$ and $14.7 \pm 4.5 \mathrm{mg} / \mathrm{L}, \mathrm{CI}=12.7-16.6 \mathrm{mg} / \mathrm{L}$, respectively) and patients with late-onset MG $(\mathrm{n}=52,24.8 \pm$ $8.8 \mathrm{mg} / \mathrm{L}, \mathrm{CI}=22.4-27.2 \mathrm{mg} / \mathrm{L}$ and $16.4 \pm 6.2 \mathrm{mg} / \mathrm{L}, \mathrm{CI}=$ $14.8-18.1 \mathrm{mg} / \mathrm{L}$, respectively) (figure $2, \mathrm{C}$ and $\mathrm{D}$ ). Twelve patients with MG had an abnormal thymus, including 2 patients with thymoma and 10 patients with thymus hyperplasia. An analysis of those patients revealed no difference in the $\kappa$ FLC and $\lambda$ FLC levels between patients with thymic pathology $(23.8 \pm 8.2 \mathrm{mg} / \mathrm{L}, \mathrm{CI}=19.2-28.4$ and $16.8 \pm 4.9 \mathrm{mg} / \mathrm{L}$, $\mathrm{CI}=14.0-19.5 \mathrm{mg} / \mathrm{L}$, respectively) and those patients without $(22.6 \pm 6.6 \mathrm{mg} / \mathrm{L}, \mathrm{CI}=20.7-24.4$ and $15.6 \pm 4.7 \mathrm{mg} / \mathrm{L}, \mathrm{CI}=$ $14.3-16.9 \mathrm{mg} / \mathrm{L}$, respectively, figure 2, E and F). Twenty-eight of the patients were being regularly treated by IV immunoglobulin (IVIg) at a dose of $0.4 \mathrm{~g} / \mathrm{kg}$ every 3-6 weeks. A blood sample from these patients was always taken just before the next IVIg treatment. There was no difference in the $\kappa$ FLC and $\lambda$ FLC levels between the patients with IVIg-treated MG (22.7 $\pm 7.8 \mathrm{mg} / \mathrm{L}, \mathrm{CI}=19.8-25.6$ and $16.4 \pm 5.3 \mathrm{mg} / \mathrm{L}, \mathrm{CI}=$ $14.4-18.3 \mathrm{mg} / \mathrm{L}$, respectively) and the patients with non-IVIgtreated MG $(23.0 \pm 6.1 \mathrm{mg} / \mathrm{L}, \mathrm{CI}=21.0-25.1$ and $15.7 \pm 4.2$ $\mathrm{mg} / \mathrm{L}, \mathrm{CI}=14.3-17.1 \mathrm{mg} / \mathrm{L}$, respectively). There were no differences in $\kappa$ FLC and $\lambda$ FLC levels between patients who were treated with pyridostigmine alone $(\mathrm{n}=22,22.4 \pm 6.6 \mathrm{mg} /$ $\mathrm{L}, \mathrm{CI}=19.6-25.2$ and $15.5 \pm 3.9 \mathrm{mg} / \mathrm{L}, \mathrm{CI}=14.0-17.1 \mathrm{mg} / \mathrm{L}$, respectively) and those who were also treated with prednisone and/or azathioprine but not IVIg $(\mathrm{n}=22,22.6 \pm 3.3 \mathrm{mg} / \mathrm{L}$, 

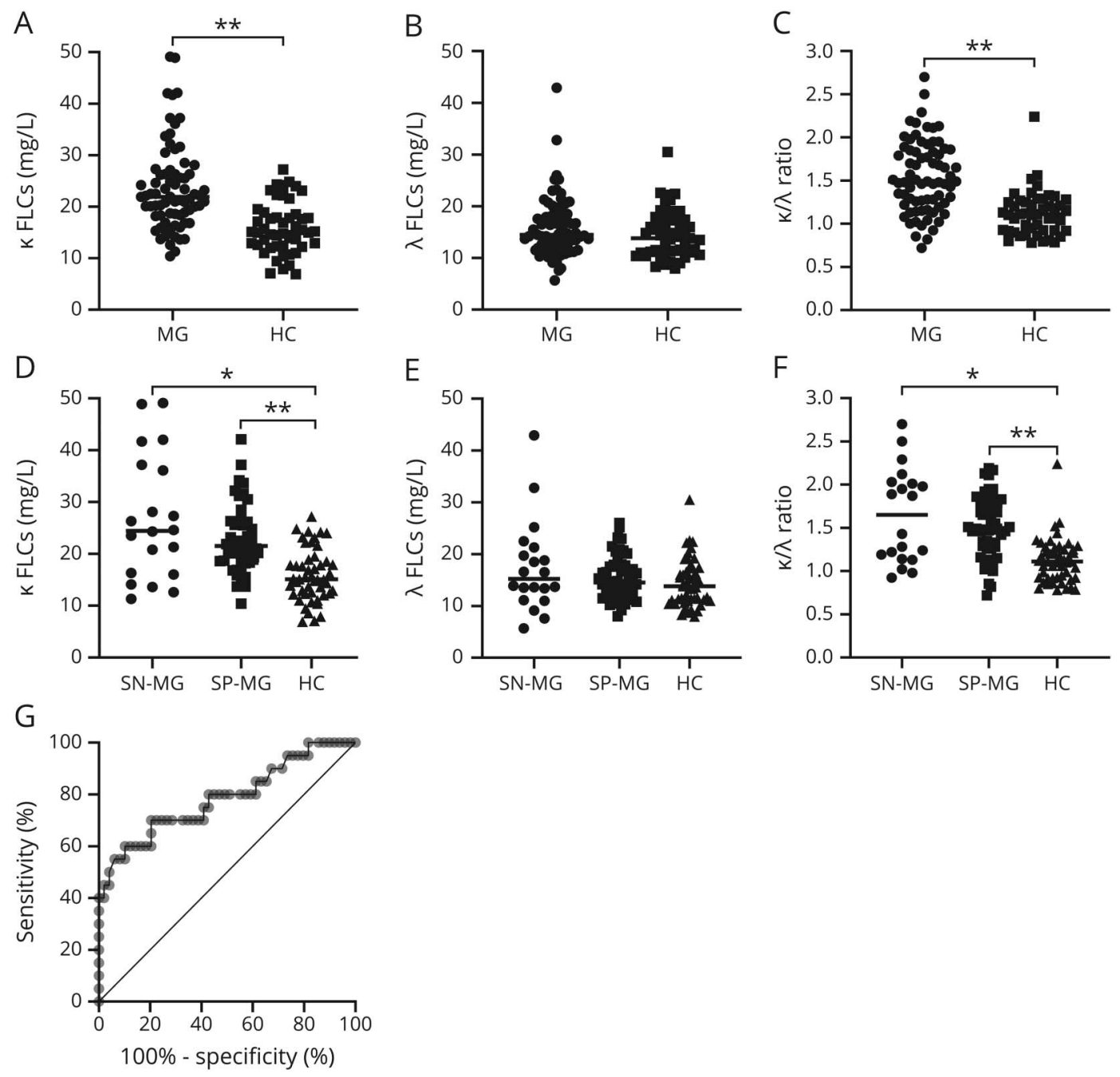

Free light chain (FLC) levels in the sera of patients with seropositive myasthenia gravis (SP-MG) and patients with double seronegative MG (SN-MG). Serum $\kappa(A)$ and $\lambda(B) F L C$ levels and the $\kappa / \lambda$ ratio (C) in patients with MG and healthy controls (HCs). Serum $K(D)$ and $\lambda(E) F L C$ levels and the $K / \lambda$ ratio $(F)$ in patients with double SN-MG, in patients with SP-MG for antiacetylcholine receptor antibody, and in HCS. A receiver operating characteristic curve for $\mathrm{K}$ FLC in patients with double SN-MG (G). Significant $p$ values for the $t$ test and Dunnett T3 multiple comparisons test are displayed: ${ }^{*} p<0.01$; and ${ }^{* *} p<0.0001$.

$\mathrm{CI}=21.2-23.9 \mathrm{mg} / \mathrm{L}$ and $14.3 \pm 4.4 \mathrm{mg} / \mathrm{L}, \mathrm{CI}=12.5-16.2$ $\mathrm{mg} / \mathrm{L}$, respectively) and those who were treated with IVIg. One patient was treated with rituximab.

\section{Consistently high к FLC levels}

To assess the reliability of FLC measurements, serum was collected once more from 28 patients with MG at an average interval of 6 months. The statistical analysis with a paired $t$ test revealed no significant difference between the 2 samples (22.3 $\pm 6.8 \mathrm{mg} / \mathrm{L}, \mathrm{CI}=19.8-24.8 \mathrm{mg} / \mathrm{L}$ vs $21.4 \pm 7.4 \mathrm{mg} / \mathrm{L}, \mathrm{CI}=$ $18.6-24.2 \mathrm{mg} / \mathrm{L})$. The mean \pm SD of percentage of change between the sample pairs was $16.0 \% \pm 11.9 \%, \mathrm{CI}=11.6-20.4$.

\section{Discussion}

The search for the biological role and possible clinical application of FLC in various autoimmune diseases has become an area of growing interest. A number of studies have demonstrated that FLCs are not a waste of immunoglobulin synthesis but rather active molecules with immunologic properties. FLCs have been shown to participate in several key processes of immune responses. They are necessary to adjust polymorphonuclear function and stimulation, ${ }^{20}$ they cause mast cell degranulation that releases proinflammatory mediators, ${ }^{21}$ and they may have direct toxicity in the kidney. ${ }^{9}$ Overproduction of FLC may occur after an excess of antibody production by B cells, usually as a result of chronic immune stimulation. Therefore, the measurement of FLC has been proposed as a biomarker of B-cell activity. ${ }^{10}$

Little is known about FLC in MG. The main result of our current study is the finding that patients with MG have higher levels of serum $\kappa$ FLC but not of $\lambda$ FLC compared 

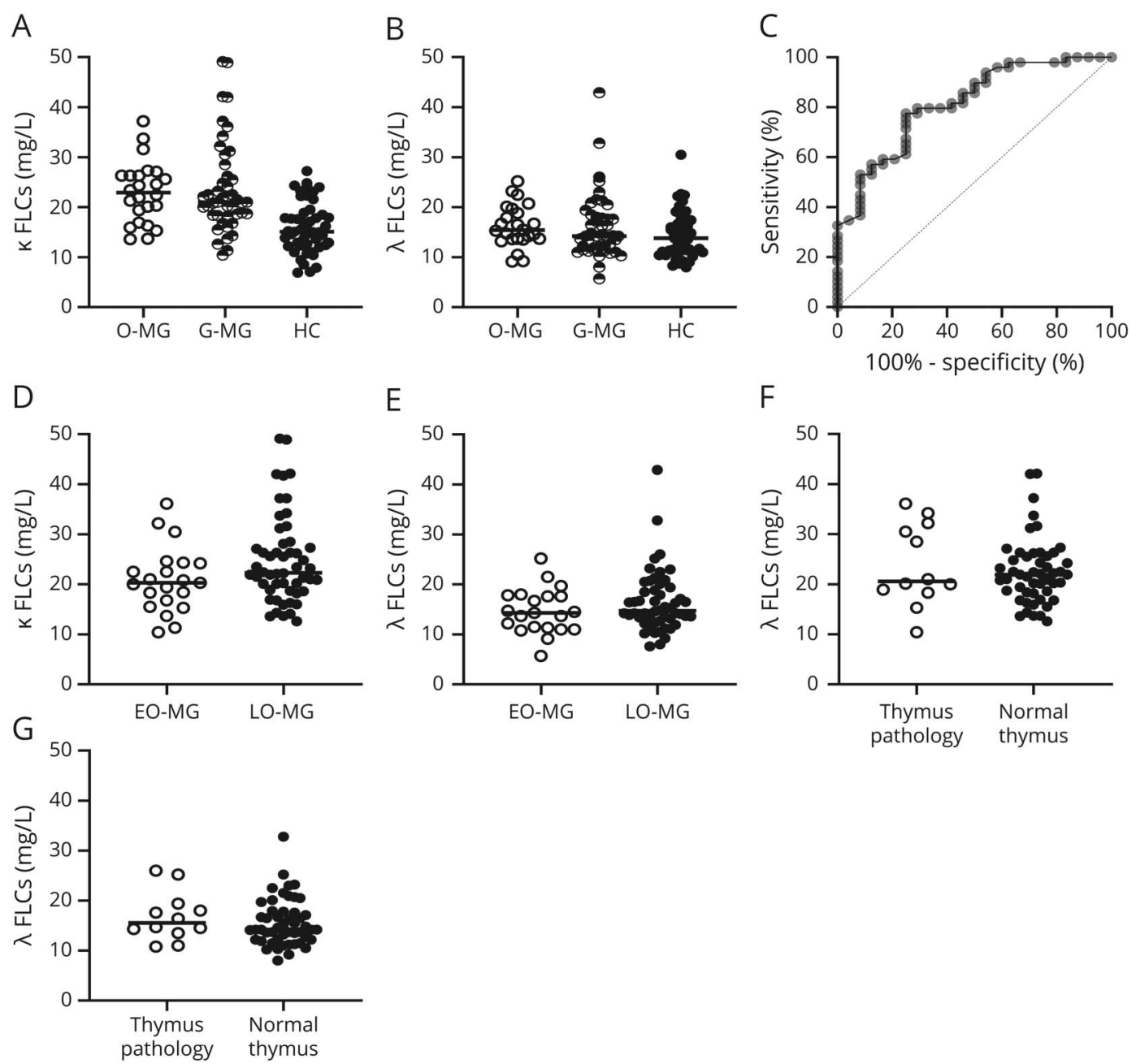

Serum $\mathrm{k}(\mathrm{A})$ and $\lambda(B)$ free light chain (FLC) levels in patients with pure ocular myasthenia gravis (O-MG) and patients with generalized myasthenia gravis (G$M G)$. A receiver operating characteristic curve for $\mathrm{K} F \mathrm{CC}$ in patients with O-MG (C). Serum $\mathrm{K}(\mathrm{D})$ and $\lambda(\mathrm{E}) \mathrm{FLC}$ levels in early-onset myasthenia gravis (EO-MG, age $\leq 50$ years) and late-onset myasthenia gravis (LO-MG, age $>50$ years). Serum $\mathrm{k}(\mathrm{F})$ and $\lambda(\mathrm{G}) \mathrm{FLC}$ levels in MG patients with thymus pathology and normal thymus. $\mathrm{HC}=$ healthy control.

with HCs. Furthermore, and even more important, we observed that the levels of $\kappa$ FLC are high in patients with double SN-MG compared with HCs. This is a heretofore unreported immunologic finding of double SN-MG. The differential diagnosis of patients with suspected SN-MG is according to the patient's specific clinical expression, and the diagnostic investigation is by verification of the clinical course and manifestations, blood tests, electromyographic tests, and imaging studies. For patients who were not diagnosed with another disease, a high level of $\kappa$ FLC and of the $\kappa / \lambda$ ratio may serve as a supportive biomarker for $M G$, when there is no comorbidity with a known medical condition that is associated with high FLC levels. Also, none of our patients with double SN-MG were diagnosed with any other diseases known to have high FLC levels, 2 of our patients with double SN-MG tested positive to autoantibodies ( 1 had positive ANA, anti-dsDNA, and anti-histone, and the other had positive TPO). Because the FLC levels in these patients were low, and therefore did not contribute to the overall increase in $\kappa$ FLC levels in this patient group, we did not exclude them from the analysis.

It is important to emphasize that being a biomarker does not make $\kappa$ FLC a diagnostic test for MG, as the antibodies against postsynaptic antigen of the neuromuscular junction, but at a high value and under the above-mentioned clinical conditions, it supports the diagnosis of MG. This finding suggests overactivity of plasma cells in this patient subgroup. It is conceivable, therefore, that there is a postsynaptic-directed antibody production that has not yet been identified, or that the current methods are not sensitive enough to detect it in this subgroup of patients with double SN-MG. ${ }^{22}$

Clinical presentation, age at MG onset, and the presence of thymus pathology did not affect the $\kappa$ FLC levels that were high in both O-MG and G-MG patients as well as among the early- 
onset and late-onset MG patients. O-MG is often part of the differential diagnosis of disorders of the brainstem, ocular motor nerves, and eye muscles, and the confirmatory tests of edrophonium, serum AChR antibodies, and electromyographic evaluations may fail to support the diagnosis of $\mathrm{O}-\mathrm{MG} .{ }^{23}$ Our results suggest that high levels of $\kappa$ FLC can serve as a biomarker to support the diagnosis of O-MG in these cases.

Twenty-eight of our patients with MG were treated with IVIg, but we did not find any effect of this therapy on their FLC levels when their blood sample was drawn just before the next scheduled treatment. This observation can be explained by the fact that although IVIg solutions contain FLC, their half-life is only a few hours. There were also no differences in $\kappa$ FLC levels in these patients and the patients who were treated with pyridostigmine alone or with immunosuppressive agents without IVIg. Our results, therefore, suggest no treatment effect on $\kappa$ FLC levels.

Our results of elevated $\kappa$ FLC levels in patients with MG are in line with recent observations in 34 serum samples from 17 AChR-positive and 13 MuSK-positive patients. ${ }^{18}$ However, those authors found a significant increase in free $\lambda$ chain levels as well. A review of their data reveals that the patients' free $\lambda$ chain levels were higher than those of the controls but were within the normal range, whereas the $\kappa / \lambda$ ratio was significantly higher in both MG groups, which indicates substantial increases in free $\kappa$ FLC. The explanation for increased $\kappa$ FLC levels in autoimmune diseases is not clear. This finding could possibly be explained by the dominance of $\kappa$ FLC in humans because the $\kappa$ chain is rearranged first during IgG production and is quantitatively more common. ${ }^{16,24}$ Furthermore, $\lambda$ FLC is usually dimeric in form, whereas $\kappa$ FLC is generally monomeric but can exist as noncovalently linked dimers. ${ }^{25}$ In addition, the 2 forms of FLC probably serve as different modulators of the immunologic response because $\lambda$ FLCs are more effective silencers of autoreactive B cells, ${ }^{26}$ which may explain why the $\kappa$ FLC level is more elevated in classic autoimmune diseases, such as MG.

A high $\kappa$ FLC level was also shown to be associated and to have prognostic value in several autoimmune conditions. Specifically, serum $\kappa$ chains and $\kappa / \lambda$ ratios were significantly higher in systemic sclerosis and correlated with disease activity. ${ }^{11}$ Moreover, $\kappa$ chains were significantly and strongly correlated with disease activity in Sjögren syndrome, and patients with systemic lupus erythematosus demonstrated elevated concentrations of serum FLC (mainly $\kappa$ chains), with a strong inverse correlation having been found between the $\kappa$ chain levels and the $\mathrm{C} 3$ levels. ${ }^{11,12}$ CSF $\kappa$ FLC levels have a high sensitivity and specificity for the diagnosis of MS, and they can predict conversion from a clinically isolated syndrome to MS. ${ }^{15-17}$

The diagnosis of MG may be challenging, especially in patients with no detectable antibodies in their serum. To the best of our knowledge, this is the first description of elevated $\kappa$ FLC levels in patients with double SN-MG. The measurement of $\kappa$ FLC is reliable, inexpensive, and rapid and therefore readily available for supporting the possible diagnosis of these patients.
Our study has several limitations. The number of SN patients is relatively small because only about $10 \%$ of patients with $M G$ are $S N$. We intentionally recruited a higher proportion of SN patients who comprised $27.4 \%$ of the studied MG group to be able to test the hypothesis of increased FLC levels in this patient subgroup. Indeed, we found significantly increased levels of $\kappa$ FLC in patients with double SN-MG. A larger group of SN subjects would have allowed stronger support for these results. Anti-LRP4 antibody and anticlustered AChR antibody were not evaluated, and anti-MuSK was not detected in our patients. Therefore, we could not study the levels of FLC in patients who are positive to one or more of these autoantibodies or in patients who are also negative for anti-LRP4 and anticlustered AChR antibodies. Because these tests are not available in many centers, we believe that the relatively simple test for determining FLC levels can support the diagnosis of MG in such situations. Our control group comprised healthy individuals and not patients with other diseases that can mimic MG; therefore, our conclusions are limited to cases that those mimickers were ruled out.

Elevation in $\kappa$ FLC levels is not specific for MG, and it can be found in hematologic malignancies and in other autoimmune diseases. Therefore, $\kappa$ FLC can serve as a biomarker only in patients whose clinical manifestations suggest the possibility of MG and who do not have any other disorder known to be associated with increased $\kappa$ FLC levels. In conditions in which the only diagnostic support for MG is a high $\kappa$ FLC level, and after ruling out other disorders that are associated with high $\kappa$ FLC levels, it would be appropriate to consider performing hematologic and immunologic tests for these disorder markers to rule them out. Because we did not assess the association between FLC levels with disease activity, severity, and response to therapy, we cannot comment on the use of FLC as a biomarker for MG activity, as reported in other autoimmune diseases, ${ }^{9,10,14,25}$ or for the possibility of its being a marker of response to therapy. Further investigation is needed to study these questions.

In conclusion, our data support the use of $\kappa$ FLC as a biomarker for $M G$, especially in patients with double SN-MG and in patients suspected of having O-MG for which a high $\kappa$ FLC level seems to be specific for MG.

\section{Acknowledgment}

The authors thank Ms. Esther Eshkol, the institutional medical copyeditor, for editing the manuscript for nonintellectual content.

\section{Study funding}

The study was funded in part by The Binding Site Group Ltd. and by Medison Pharmaceuticals Ltd.

\section{Disclosure}

The authors report no disclosures relevant to the manuscript. Go to Neurology.org/NN for full disclosures. 


\section{Publication history}

Received by Neurology: Neuroimmunology \& Neuroinflammation February 29, 2020. Accepted in final form May 29, 2020.

\section{Appendix Authors}

\begin{tabular}{lll}
\hline Name & Location & Contribution \\
\hline $\begin{array}{l}\text { Adi Wilf- } \\
\text { Yarkoni, } \\
\text { MD }\end{array}$ & $\begin{array}{l}\text { Rabin Medical Center } \\
\text { Israel, Petach Tikva, Israel }\end{array}$ & $\begin{array}{l}\text { Analysis or interpretation of the } \\
\text { data and drafting or revising } \\
\text { the manuscript for intellectual } \\
\text { content }\end{array}$ \\
\hline $\begin{array}{l}\text { Yifat } \\
\text { Alkalay, } \\
\text { PhD }\end{array}$ & Tel Aviv Sourasky Medical & $\begin{array}{l}\text { Major role in the acquisition of } \\
\text { data }\end{array}$ \\
\hline $\begin{array}{l}\text { Talma } \\
\text { Brenner, } \\
\text { PhD }\end{array}$ & $\begin{array}{l}\text { Hadassah-Hebrew } \\
\text { University Medical Center, }\end{array}$ & $\begin{array}{l}\text { Major role in the acquisition of } \\
\text { data }\end{array}$ \\
\hline $\begin{array}{l}\text { Arnon } \\
\text { Karni, } \\
\text { MD, PhD }\end{array}$ & Tel Aviv Sourasky Medical & $\begin{array}{l}\text { Design or conceptualization of } \\
\text { the study and drafting or }\end{array}$ \\
& & $\begin{array}{l}\text { revising the manuscript for } \\
\text { intellectual content }\end{array}$ \\
\hline
\end{tabular}

\section{References}

1. Gilhus NE. Myasthenia gravis. N Engl J Med 2017;376:e25.

2. Gilhus NE, Verschuuren JJ. Myasthenia gravis: subgroup classification and therapeutic strategies. Lancet Neurol 2015;14:1023-1036.

3. Berrih-Aknin S, Le Panse R. Myasthenia gravis: a comprehensive review of immune dysregulation and etiological mechanisms. J Autoimmun 2014;52:90-100.

4. Zisimopoulou P, Brenner T, Trakas N, Tzartos SJ. Serological diagnostics in myasthenia gravis based on novel assays and recently identified antigens. Autoimmun Rev 2013;12:924-930.

5. Berrih-Aknin S, Frenkian-Cuvelier M, Eymard B. Diagnostic and clinical classification of autoimmune myasthenia gravis. J Autoimmun 2014;48-49:143-148.

6. Vincent A, Newsom-Davis J. Acetylcholine receptor antibody as a diagnostic test for myasthenia gravis: results in 153 validated cases and 2967 diagnostic assays. J Neurol Neurosurg Psychiatry 1985;48:1246-1252.

7. Evoli A, Tonali PA, Padua L, et al. Clinical correlates with anti-MuSK antibodies in generalized seronegative myasthenia gravis. Brain 2003;126:2304-2311.
8. Zisimopoulou P, Evangelakou P, Tzartos J, et al. A comprehensive analysis of the epidemiology and clinical characteristics of anti-LRP4 in myasthenia gravis. J Autoimmun 2014;52:139-145.

9. Esparvarinha M, Nickho H, Mohammadi H, Aghebati-Maleki L, Abdolalizadeh J, Majidi J. The role of free kappa and lambda light chains in the pathogenesis and treatment of inflammatory diseases. Biomed Pharmacother 2017;91:632-644.

10. Napodano C, Pocino K, Rigante D, et al. Free light chains and autoimmunity. Autoimmun Rev 2019;18:484-492.

11. Bosello S, Basile U, De Lorenzis E, et al. Free light chains of immunoglobulins in patients with systemic sclerosis: correlations with lung involvement and inflammatory milieu. J Clin Pathol 2018;71:620-625.

12. Chiche L, Cournac JM, Mancini J, et al. Normalization of serum-free light chains in patients with systemic lupus erythematosus upon rituximab treatment and correlation with biological disease activity. Clin Rheumatol 2011;30:685-689.

13. Gottenberg JE, Aucouturier F, Goetz J, et al. Serum immunoglobulin free light chain assessment in rheumatoid arthritis and primary Sjogren's syndrome. Ann Rheum Dis 2007;66:23-27.

14. Gulli F, Napodano C, Marino M, et al. Serum immunoglobulin free light chain levels in systemic autoimmune rheumatic diseases. Clin Exp Immunol 2020;199:163-171.

15. Hassan-Smith G, Durant L, Tsentemeidou A, et al. High sensitivity and specificity of elevated cerebrospinal fluid kappa free light chains in suspected multiple sclerosis. J Neuroimmunol 2014;276:175-179.

16. Ramsden DB. Multiple sclerosis: assay of free immunoglobulin light chains. Ann Clin Biochem 2017;54:5-13.

17. Senel M, Mojib-Yezdani F, Braisch U, et al. CSF free light chains as a marker of intrathecal immunoglobulin synthesis in multiple sclerosis: a blood-CSF barrier related evaluation in a large cohort. Front Immunol 2019;10:641.

18. Basile U, Marino M, Napodano C, et al. Serological immunoglobulin-free light chain profile in myasthenia gravis patients. J Immunol Res 2018;2018:9646209.

19. Kerty E, Elsais A, Argov Z, Evoli A, Gilhus NE. EFNS/ENS guidelines for the treatment of ocular myasthenia. Eur J Neurol 2014;21:687-693.

20. Braber S, Thio M, Blokhuis BR, et al. An association between neutrophils and immunoglobulin free light chains in the pathogenesis of chronic obstructive pulmonary disease. Am J Respir Crit Care Med 2012;185:817-824.

21. Redegeld FA, van der Heijden MW, Kool M, et al. Immunoglobulin-free light chains elicit immediate hypersensitivity-like responses. Nat Med 2002;8:694-701.

22. Devic P, Petiot P, Simonet T, et al. Antibodies to clustered acetylcholine receptor: expanding the phenotype. Eur J Neurol 2014;21:130-134.

23. Kusner LL, Puwanant A, Kaminski HJ. Ocular myasthenia: diagnosis, treatment, and pathogenesis. Neurologist 2006;12:231-239.

24. van der Heijden M, Kraneveld A, Redegeld F. Free immunoglobulin light chains as target in the treatment of chronic inflammatory diseases. Eur J Pharmacol 2006;533:319-326.

25. Boivin D, Provencal M, Gendron S, et al. Purification and characterization of a stimulator of plasmin generation from the antiangiogenic agent Neovastat: identification as immunoglobulin kappa light chain. Arch Biochem Biophys 2004;431:197-206.

26. Wardemann H, Hammersen J, Nussenzweig MC. Human autoantibody silencing by immunoglobulin light chains. J Exp Med 2004;200:191-199. 


\title{
Neurology \\ Neuroimmunology \& Neuroinflammation
}

\author{
High $\kappa$ free light chain is a potential biomarker for double seronegative and ocular \\ myasthenia gravis \\ Adi Wilf-Yarkoni, Yifat Alkalay, Talma Brenner, et al. \\ Neurol Neuroimmunol Neuroinflamm 2020;7; \\ DOI 10.1212/NXI.0000000000000831
}

This information is current as of July 14, 2020

\section{Updated Information \& \\ Services \\ References \\ Subspecialty Collections}

Permissions \& Licensing

Reprints including high resolution figures, can be found at:

http://nn.neurology.org/content/7/5/e831.full.html

This article cites 26 articles, 4 of which you can access for free at: http://nn.neurology.org/content/7/5/e831.full.html\#\#ref-list-1

This article, along with others on similar topics, appears in the following collection(s):

Autoimmune diseases

http://nn.neurology.org//cgi/collection/autoimmune_diseases

Class III

http://nn.neurology.org//cgi/collection/class_iii

Myasthenia

http://nn.neurology.org//cgi/collection/myasthenia

Information about reproducing this article in parts (figures,tables) or in its entirety can be found online at:

http://nn.neurology.org/misc/about.xhtml\#permissions

Information about ordering reprints can be found online:

http://nn.neurology.org/misc/addir.xhtml\#reprintsus

Neurol Neuroimmunol Neuroinflamm is an official journal of the American Academy of Neurology.

Published since April 2014, it is an open-access, online-only, continuous publication journal. Copyright

Copyright $\odot 2020$ The Author(s). Published by Wolters Kluwer Health, Inc. on behalf of the American

Academy of Neurology.. All rights reserved. Online ISSN: 2332-7812.

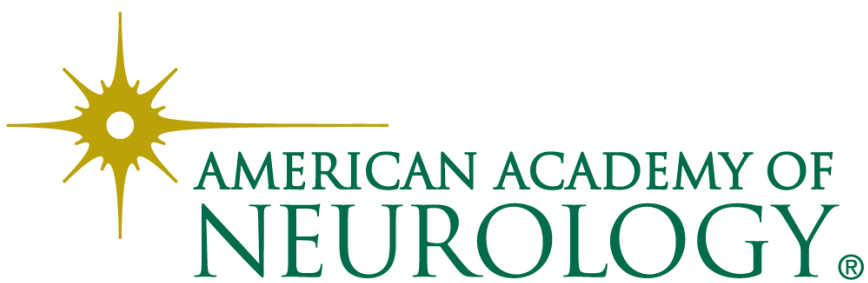

